\title{
Artery of percheron stroke: a case report
}

\section{Case report}

A 42-year-old female is admitted to hospital with a lower level of consciousness. Toxic-metabolic causes were excluded, orotracheal intubation measures were taken and sent to the Intensive Care Unit (ICU), but there is no return to the level of consciousness. ${ }^{1,2}$ Computed tomography image examinations were performed, revealing hypodensity in thalamic regions, and then magnetic resonance imaging, showing an infarction area in thalamic regions bilaterally. She spent 15 days in the Intensive Care Unit, progressing with a worsening of the general condition, pneumonia and dying from sepsis. ${ }^{3}$

\section{Discussion}

The Artery of Percheron (AOP) is an anatomical variation, present in about 4 to $12 \%$ of the population, which consists of a branch of one of the posterior cerebral arteries irrigating the entire paramedian portion of the territory of both thalamus and part of the rostral region of the midbrain. Occlusions in this artery can result in bitalamic infarctions, which is a rare condition that accounts for about $0.6 \%$ of all brain infarctions. These occlusions are caused mainly by the Small Vessel Disease, resulting from the accumulation of a plaque causing narrowing of the artery, and due to embolizations coming from the heart, aorta or cervicocerebral arteries. In addition to occlusions, venous drainage thrombosis of the thalamus can also cause infarctions in this region, being lighter and with rapid clinical recovery. ${ }^{4}$

The main symptoms resulting from infarction due to AOP occlusion are changes in the level of consciousness such as disorientation, confusion and hypersolence, in addition to deep coma, akinetic mutism, amnesic syndrome, dysarthria and aphasic disorders, hypophonia and dysprosia, vertical gaze paralysis. Imaging exams are extremely important in diagnosis. Computed Tomography (CT) and angioCT images can be useful to detect bitalamic infarction; however, to determine its etiology, Magnetic Resonance Imaging demonstrates the type of vascular occlusion, in addition to providing the differential diagnosis with other relevant pathologies, mainly toxic-metabolic causes, such as carbon monoxide poisoning, Wenicke's encephalopathy and osmotic myelinolysis, and venous causes, such as the thalamus venous drainage thrombosis. The latter being an important distinction, as it requires different prognoses and other types of therapies. 5,6

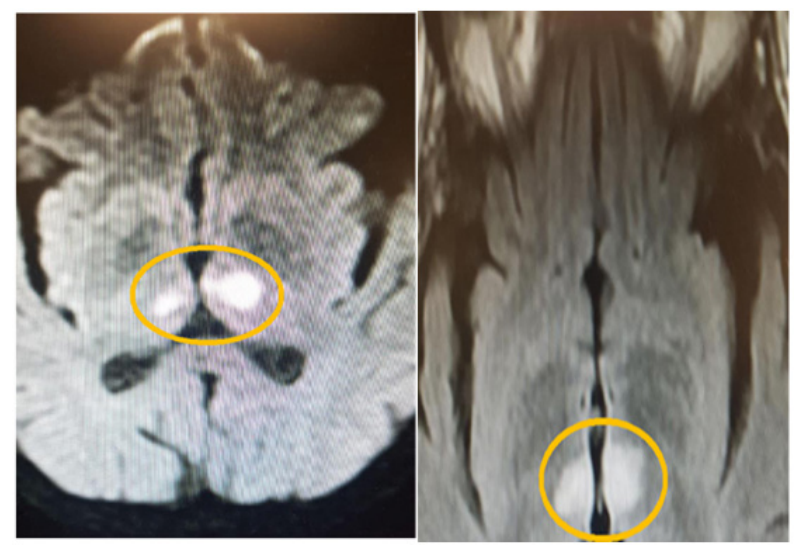

Volume 6 Issue 2 - 202I

\author{
Marcelo Zalli, 'Victor Cubas Schulz, ${ }^{2}$ \\ Henrique Orefice Farah, ${ }^{3}$ Matheus Soares \\ Flor $^{3}$ \\ 'Professor of Neurology at UNIVALI, Brazil \\ ${ }^{2}$ Neurologist at Unimed Litoral and Centro Médico Madrid, \\ Spain \\ ${ }^{3}$ Medical students at UNIVALI, Brazil
}

Correspondence: Dr. Marcelo Zalli, Professor of Neurology UNIVALI Itajaí-SC/, Neurologist at Madrid Medical Center and Unimed Litoral Hospital. Postgraduate in Dementia and Neurodegenerative Diseases, Member of the ALZ - Alzheimer's Association and the Brazilian Academy of Neurology, Brazil, Email zalli.neurounivali@gmail.com

Received: March 03, 2021 | Published: April 08, 202I

\section{Conclusion}

(Figure 1) Arterial bitalamic infarcts have high rates of morbidity and persistent deficits, with a worse prognosis when symmetrically affecting both thalamus. Unfortunately, these patients are rarely submitted to thrombolysis and adequate ventilatory support. Our report highlights the importance and need to make a quick diagnosis and intervention, especially in those patients who vary between unconscious and comatose states, as these infarctions are more severe and bring consequences that last for a lifetime or even lead to death. Recalling also the relevance of performing imaging tests for the distinction with other causes to institute appropriate therapy in a timely manner.

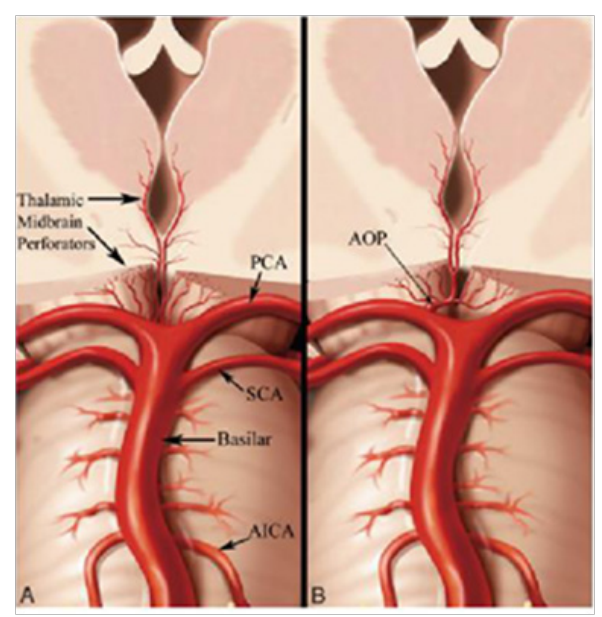

Figure I (A) Talamic Arterial Vasculation. (B) Artery of Percheron irrigating both sides of the paramedian portion of the talamus.

\section{Acknowledgement}

None. 


\section{Funding}

None.

\section{Conflicts of interest}

None.

\section{References}

1. Agarwal N, Arpan T, David RH, et al. Current differential diagnoses and treatment options of vascular occlusions presenting as bilateral thalamic infarcta review of the literature. Journal of Neurointerventional Surgery. 2012;5(5):419-425.

2. Antonio A, Hernán MP, Juan CV, et al. Clinical Spectrum of Artery of Percheron Infarct: Clinical-Radiological Correlations. Journal of Stroke And Cerebro vascular Diseases. 2017;23(5):1083-1088.
3. Carrie C, Garnier S, Filloux B, et al. Infarctus bithalamique sur occlusion de l'artère de Percheron : difficultés de diagnostic et de prise en charge en réanima tion. Annales Françaises D’anesthésie Et de Réanimation. 2012;31(11):926-927.

4. Sarah D, Philippe D, Robin L, et al. Non-REM sleep EEG pattern in acute bithalamic paramedian infarction. Acta Neurologica Belgica. 2017;117(4):921-924.

5. Hoing A, Ruth E, Roni E, et al. Acute bithalamic infarct manifesting as sleep-like coma: A diagnostic challenge. Journal of Clinical Neuroscience. 2016;34:81-85.

6. Nicholas AL, Wright B, Castillo M, et al. Artery of Percheron Infarction: Imaging Patterns and Clinical Spectrum. American Journal of Neuroradiology. 2010;31(7):1283-1289. 